\title{
ENSAIO BIBLIOGRÁFICO \\ A INTERPRETAÇÃO DO NAZISMO, NA VISÃO DE NORBERT ELIAS
}

Boris Fausto

\begin{abstract}
Elias, Nobert. 1996. The Germans. Pow er Struggle and the Development of Habitus in the Nineteenth and Twentieth Centuries. New York: Columbia University Press. 494 pp.
\end{abstract}

As categorias explicativas de inspiração liberal ou marxista, tal como eram formuladas nos primeiros decênios deste século, foram insuficientes para dar conta das grandes tempestades sociopolíticas de nossa época, dentre as quais se destacam - em posição relevante - o fascismo e o nazismo.

Há várias razões para a perplexidade. Em primeiro lugar, esses dois regimes subverteram a significação tradicional da direita no espectro político. Tanto um quanto o outro incorporaram simbolicamente o fascínio das revoluções, rompendo com o quadro ideológico da direita clássica, vinculada, com freqüência, à I greja e ao pensamento católico (Furet 1995). Não é possível, pois, interpretar o fenômeno nazista sem levar em conta a irrupção das massas na arena política, embaladas pelo sonho do "socialismo nacional", da unidade da pátria e, no caso específico do nazismo, da supremacia da raça ariana.

A fora isso, o nazismo representou uma mudança de qualidade - se é que se pode brincar nesse terreno com as palavras - no tocante à utilização da teoria da superioridade racial e do anti-semitismo. $\mathrm{O}$ anti-semitismo que percorreu a história do mundo ocidental não foi o núcleo fundamental articulador das diferentes formações sociais, o que não significa negar sua importância como instrumento político. Mas nem a discriminação genérica, nem os pogroms, nem mesmo a expulsão dos judeus da Península Ibérica, para ficar em um exemplo histórico ancestral, equivalem aos objetivos de um regime que, desde o início da Segunda Guerra M undial, decidiu erradicar da face da terra o "bacilo judaico", embora levasse algum tempo para encontrar a fórmula mais eficaz de extermínio.

Do ponto de vista da prática política, as interpretações da III Internacional, que não correspondem necessariamente às do marxismo oci- 
dental, derivaram da análise inicial do fascismo, em meados da década de 20, chegando com algumas variantes aos últimos tempos da chamada República Democrática Alemã. A teoria explicativa da III Internacional, em termos simplificados, concentrava-se na análise econômica e na luta de classes. A partir da concepção leninista do imperialismo, afirmava que, em face do colapso iminente e inelutável do capitalismo, os elementos mais reacionários e mais poderosos do capital financeiro tinham desviado os movimentos de massa nascidos no após-guerra, a fim de manipulálos a serviço de seus interesses. Em última análise, os dirigentes fascistas e nazistas não passariam de lacaios do grande capital financeiro, um instrumento eficaz da repressão à classe operária organizada e da garantia da manutenção de seus lucros.

Há uma parcela de verdade nessa interpretação, mas apenas uma parcela. É um dado irrecusável que, se os representantes do grande capital colaboraram com a ascensão dos nazistas, em face do espectro real ou imaginário do comunismo, sempre pretenderam deles servir-se, na qualidade sobranceira de aristocratas diante de ativistas pequeno-burgueses semi-educados. Entretanto, definir a relação entre os grandes personagens do setor financeiro e da indústria alemã, de um lado, e o Partido Nazista em que avulta a figura de Hitler, de outro, como correspondente à de senhor e lacaio, é certamente equivocado. Embora não tenha ocorrido uma dominação do tipo sugerido por essa imagem, a inversão do relacionamento torna-se mais cabível. Ou seja, o Partido-Estado nazista determinou os rumos fundamentais da política, encarando com desprezo uma grande burguesia pragmática cuja colaboração Ihe era, entretanto, indispensável.

The Germans, livro de ensaios de Norbert Elias publicado pouco antes de sua morte, tem como um de seus eixos a interpretação do nazismo, seja no que diz respeito às suas raízes históricas, seja no que se refere às possibilidades de sua transfigurada ressurreição. Isto me parece justificar a seleção desse tema central na análise do livro, embora outras questões de um trabalho tão denso fiquem aqui intocadas.

Desde logo, convém assinalar que o autor acrescenta mais um elemento significativo às dificuldades de se entender o nazismo. Trata-se, em suas palavras, da tendência a dar importância secundária a crenças sociais e políticas, tomando-as como uma espécie de espuma, como "ideologias", diante dos reais interesses de grupos ou classes (:312). Tomando como exemplo a decisão de pôr em prática o plano de "solução final para o problema judeu", Elias assinala que ela não se explica mediante critérios que costumamos chamar de racionais ou realistas. Sem 
negar a utilidade secundária de certos aspectos da decisão, ela constituiu, em essência, a realização de uma crença central e profundamente enraizada no movimento nacional-socialista desde o seu início. A crença de que a grandeza presente e futura da Alemanha e de toda a "raça ariana" dependia da luta pela "pureza racial"; essa "pureza", concebida em termos biológicos, impunha o afastamento e, no limite, a destruição dos grupos humanos "inferiores", cujo epítome era representado pela "raça" judaica.

Um pressuposto da visão da história, assumida por Elias, é lembrado no prefácio, escrito por Eric Dunning e Stephen Mennell. O processo civilizador - conceito e tema constitutivo de sua obra mais conhecida (Elias 1993) - não é sinônimo de história-progresso, pois está sujeito a regressões; o nazismo representa uma demonstração trágica desse fato, correspondendo, no dizer do autor, ao colapso da civilização.

Elias considera que a implantação do movimento nazista e de seu sistema de crenças é incompreensível, se nos detivermos apenas na conjuntura histórica. Sem dúvida, a profunda crise econômica aberta em 1929 e a intensificação do conflito de classes daí resultante concorreram para o triunfo do nacional-socialismo. Mas, para se entender o fenômeno em toda a sua extensão torna-se necessário, acima de tudo, considerar as características do desenvolvimento da A lemanha, através de um longo processo histórico (:316).

Ressalve-se que, por maior que seja o peso dado à história de longa duração, na perspectiva do autor, o nacional-socialismo não constituiu uma necessidade histórica. A tradição nacional alemã abriu a possibilidade da emergência desse regime que contém e potencia as características dominantes da aludida tradição.

A tualmente, há pouca discordância de que o recurso à longa duração seja indispensável para o entendimento do nazismo. Interpretações estritamente personalistas, centradas na figura de $\mathrm{Hitler}$, ou microconjunturais, perderam força ${ }^{1}$. Porém, uma vez aceita a necessidade de buscar-se um quadro mais amplo, as questões proliferam. A partir de que momento o passado histórico alemão deve ser levado em conta na tentativa de se entender a emergência e o triunfo do nazismo? Que elementos devem ser privilegiados nessa busca de nexos de sentido?

Um grande número de estudiosos tem-se concentrado na análise da sociedade e da política alemã no fim do século XIX, com perspectivas diversas e, às vezes, conflitantes. De um lado, destaca-se o papel representado por uma suposta sobrevivência de tradições autoritárias e feudais como resultado do fracasso de uma autêntica revolução burguesa. 
Em conflito com uma economia moderna e dinâmica, as forças sociais "pré-capitalistas" seriam responsáveis pela entrega do poder aos nazistas, diante da crise econômica e da emergência de um movimento de massas.

De outro lado, enfatiza-se o caráter burguês da sociedade, tratandose de explicar o nacional-socialismo não propriamente pelas "singularidades alemãs" vinculadas à idéia de uma revolução burguesa semi-abortada, mas pelas características específicas do Estado capitalista alemão, tal como se forjou a partir de fins do século XIX.

Em The Germans, Elias aparta-se dessas duas linhas interpretativas, seja do ponto de vista cronológico, seja no tocante aos elementos explicativos que seleciona e realça, na análise do processo histórico. Segundo ele, para se entender o colapso da civilização alemã, é necessário ampliar o foco cronológico da longa duração, recuando-se consideravelmente no tempo. A pós referir-se à situação instável das tribos de fala alemã, assentadas nas terras baixas da Europa a oeste do rio Elba, rodeadas de tribos inimigas, Elias analisa as características do Sacro Império Romano-Germânico, formado no século $X$ que, em seus primeiros tempos, gozava de uma posição de preeminência no contexto dos Estados europeus.

Entretanto, ao longo do tempo, enquanto muitos Estados vizinhos estavam se transformando em monarquias centralizadas e internamente pacificadas, o Sacro Império manteve uma frágil integração, diante do reforço do poder dos príncipes; este fato deu origem a intermináveis conflitos internos e foi um convite às invasões.

A partir dessa primeira caracterização, Elias traça um quadro de fraqueza da nação germânica, selecionando para tanto al guns exemplos históricos: a guerra dos Trinta Anos (1618-1648), que resultou no empobrecimento de grande parte da população alemã e na perda de um terço dessa população; a invasão do solo al emão pelas tropas de Luis XIV, no fim do século XVII; a irrupção de Napoleão à frente de um Estado centralizado, obrigando a rainha da Prússia a empreender uma fuga humilhante.

Os acontecimentos das últimas décadas do século XIX poderiam ter revertido esse quadro de fraqueza estrutural do Estado germânico. A dinâmica da eliminação interna de estados rivais tornou a casa de Brandemburgo-Prússia dominante no contexto alemão, em condições de lutar pela supremacia na Europa. De fato, ela engajou-se em uma guerra com a França - a guerra franco-prussiana de 1870-71 —, da qual saiu vitoriosa, o que Ihe permitiu promover definitivamente a unificação alemã.

Porém, diz Elias, a Alemanha definia-se como uma monarquia absoluta. $\mathrm{O}$ estágio do desenvolvimento estatal significava que as rivalidades 
dinásticas continuavam a ser decisivas nas relações com as outras grandes potências. Desse modo, os dirigentes políticos escolhidos pelo Kaiser optaram inesperadamente por uma nova guerra, sem se perguntar se a Alemanha tinha alguma possibilidade de vitória, caso os Estados Unidos entrassem no conflito ao lado de seus aliados ocidentais. $O$ resultado foi a derrota na Primeira Guerra M undial e a humilhação imposta pelo Tratado de Versalhes.

O relato sumário da história alemã, efetuado por Elias, não introduz novidades em si mesmo. A novidade diz respeito à natureza das conseqüências derivadas desse processo histórico para a compreensão da Alemanha como um todo e da catástrofe nazista, em particular. Tais conseqüências não se situam na esfera das grandes estruturas socioeconômicas e sim na formação de um habitus. A questão central de Elias consiste em entender como a história de uma nação, ao longo dos séculos, sedimentou-se no habitus de seus membros considerados individualmente (:19).

Essa referência aos "membros considerados individualmente" me parece ambígua, prestando-se a equívocos. Todo o contexto do livro e outras afirmações do autor demonstram que ele diverge de uma explicação centrada na formação da personalidade individual. Ele sugere, modestamente, estar formulando algumas considerações que permitiriam escrever a "biografia" de um Estado-sociedade, pois, tal como no desenvolvimento de uma pessoa as experiências de um tempo passado continuam a ter efeitos no presente, o mesmo ocorre no desenvolvimento de uma nação. N esse caso, trata-se de um ser coletivo, forjado em um contexto mais amplo, como Elias assinala em sua crítica da teoria da personalidade autoritária, citando expressamente Adorno (1950). Em suas palavras, o pressuposto fundamental implícito nessa teoria é o de que a pessoa, como resultado de uma estrutura familiar específica quando de seu crescimento, desenvolve a síndrome da estrutura de caráter correspondente à familiar.

Entretanto, diz Elias, a explicação, sem ser falsa é insuficiente, porque a estrutura familiar autoritária está intimamente ligada à estrutura autoritária do Estado; e, para se entender melhor a natureza dessa conexão, é necessário olhar para a organização do Estado, forjada através de um processo de longa duração.

Assentado esse ponto, é necessário precisar o conceito estratégico de habitus no pensamento de Elias e, a partir daí, discriminar os elementos que ele considera explicativos no processo de organização da sociedade e do Estado germânico. Em primeiro lugar, habitus não é sinônimo 
de "caráter nacional", expressão que o autor emprega no texto, mas sempre entre aspas. Uma clara distinção consiste no fato de que o conceito de caráter nacional tende a corresponder a um dado estrutural abrangente e pouco permeável a mutações de uma formação social, quaisquer que sejam os elementos privilegiados na constituição do "caráter nacional", tanto em uma visão racial quanto em uma visão historicista.

O conceito de habitus implica maior flexibilidade, o que se compatibiliza com os cortes e as descontinuidades da história alemã. Assim, Elias refere-se ao dilema da classe média alemã, no século XIX e no início do século XX, oscilando entre uma tendência idealista-liberal e outra conservadora-nacionalista que termina com a vitória da última, ao influxo da forma como se deu a unificação alemã. Acentua que esse fato constitui um testemunho eloqüente da natureza descontínua do desenvolvimento alemão, uma alteração de habitus que pode ser associada com clareza a uma fase específica do desenvolvimento do Estado.

A rigor, o conceito de habitus aproxima-se do de mentalidade, assumido em toda a sua extensão, como se sabe, pela historiografia francesa, a ponto de Elias referir-se a habitus nacional ou mentalidade como termos pelo menos assemel hados. Entretanto, ao contrário do que ocorre com os historiadores franceses das mentalidades, a psicologia e, sobretudo, a psicanálise parecem intervir mais do que a antropologia na constituição do conceito de habitus. A esse respeito, o autor lança mão, expressamente, de uma analogia com o método freudiano, em uma passagem em que, aliás, as fronteiras entre a psicologia individual e a psicologia coletiva não são claras. Freud, diz Elias, tratou de mostrar a conexão entre o desfecho de uma conflituosa canalização dos impulsos no desenvolvimento da personalidade e seu habitus daí resultante. M as há também conexões análogas entre o destino e as experiências de um povo, a longo prazo, e seu habitus social assim assentado. Nesse plano, ocorrem muitas vezes sintomas complexos de distúrbio que têm praticamente a força das neuroses individuais.

Tanto na situação individual quanto na coletiva, segundo Elias, é necessário empreender a mesma tarefa: trazer de volta à consciência, quase sempre em face de uma forte resistência, coisas que tinham sido esquecidas. Tal esforço, em ambos os casos, requer um autodistanciamento e, se tiver êxito, pode contribuir para a flexibilização de rígidos modelos de comportamento.

Quais as relações entre a constituição do habitus e as vicissitudes da história da Alemanha? O autor acentua que o desenrolar do processo histórico alemão, em contraste com países como a França, a Inglaterra, a 
Suécia e até a Rússia, tomou o rumo da fragmentação; disso resultou que o habitus dos membros da sociedade veio a revelar sinais de depressão e de perda de identidade. Ao longo dos séculos XVII e XVIII, a posição secundária dos estados alemães, no concerto da Europa, trouxe como conseqüência a baixa de auto-estima do povo germânico, acompanhada de um sentimento de humilhação.

Com tais características, o habitus, transmitido de geração em geração, produziu no povo alemão um desejo ardente de unidade, que emergiu recorrentemente na Alemanha em situações de crise. A auto-imagem de que os alemães não eram capazes de conviver sem discórdias e disputas encontrou expressão no sonho de encontrar um soberano ou um líder poderoso, capaz de produzir a unidade e o consenso. Da alta sensibilidade dos alemães pelas disputas internas, consideradas enfraquecedoras do ideal de unidade, resultou, por sua vez, no passado recente, uma aversão pela democracia parlamentar, com suas tensões incessantes e conflitos entre os diferentes partidos.

A forma pela qual se deu a unificação alemã e a vitória na guerra franco-prussiana provocaram uma alteração nesse quadro, após 1871. $M$ as, o ressentimento, o sentimento de inferioridade na hierarquia dos Estados europeus tiveram sua contrapartida na ênfase exagerada posta na interiorização do sentimento de grandeza e do poder da nação alemã. A valorização da força bruta, reverso de uma situação histórica passada vivida como humilhante, foi potenciada pelo êxito de uma unificação realizada sob a hegemonia dos junkers prussianos.

A partir desse quadro, podemos perceber em que características de longa duração se assenta o nazismo, depois da derrota da Alemanha na Primeira Guerra Mundial, depois de Versal hes e da implantação de um regime democrático parlamentarista, que repuseram os traços de um habitus adormecido após 1871. Se o nacional-socialismo trouxe consigo configurações terrivelmente originais, sendo a nova modalidade de antisemitismo talvez a maior delas, se assentou também em outras de que a história alemã era portadora: o desejo de unidade, a valorização da violência, a crença no "homem forte", o desprezo pela democracia. Estes fatores facilitaram, em grande medida, o ascenso ao poder de um movimento nacionalista extremista, antidemocrático e anti-semita, que constituiu uma religião social fortemente dominada pela fantasia.

Seria equivocado imaginar que Elias faz uma leitura "idealista vulgar" do processo histórico alemão. Por exemplo, a penetração do modelo prussiano na classe média alemã, como conseqüência, sobretudo, da forma como ocorreu a unificação do país, foi precedida - diz ele - de 
desentendimentos entre um setor liberal da classe média e os estratos aristocráticos da corte, expressando um verdadeiro conflito de classes, do qual a classe média liberal saiu derrotada. Entretanto, na análise do conflito, é bem mais relevante desvendar suas conseqüências no plano da constituição do habitus do que no das transformações socioeconômicas.

Identificadas as características principais do habitus, Elias refere-se à conjuntura dos anos 20 como um elemento derivado, na explicação do ascenso ao poder do nazismo. Segundo ele, a crescente influência da direita antidemocrática e do nacional-socialismo no curso daqueles anos, após os primeiros insucessos, só pode ser entendida inteiramente em conexão com a Revolução Russa. O êxito dos bolcheviques, produzindo uma aversão generalizada em amplos setores da classe média alemã e mesmo em parcela significativa da classe operária, facilitou o triunfo de Hitler e uma política condescendente dos aliados relativamente ao rearmamento alemão.

Mas, se Hitler triunfou ao destruir a República de Weimar, façanha que outros grupos paramilitares - os Freikorps - não lograram alcançar, foi porque ele foi capaz de apelar às massas e mobilizá-las, em uma situação de crise econômica e social, enquanto os Freikorps permaneceram vinculados à tradição da elite de oficiais, por mais que tal elite tenha sofrido um processo de "barbarização". A presentando-se como um homem do povo e um simples cabo do Exército, Hitler construiu eficientemente sua imagem simbólica de representante da "raça alemã", oferecendo um mundo de glória e dominação para todos os setores da sociedade dispostos a segui-lo.

A ênfase colocada por Elias na longa duração e na constituição do habitus, a fim de interpretar o nazismo, é bastante justificável e abre caminho para um campo de investigação em que se entrecruzam as diferentes disciplinas componentes das ciências humanas. Sua análise conjuntural merece, a meu ver, alguns reparos, na medida em que não dá relevância a certos elementos significativos de ordem socioeconômica e política. As referências ao quadro resultante da crise mundial iniciada em 1929 e as opções partidárias surgem em The Germans en passant, aparentemente como elementos explicativos de importância secundária. A política desastrosa do Partido Comunista alemão, nos anos 20 e nos primeiros anos da década de 30 , identificando os social-democratas, alcunhados de social-fascistas, como o inimigo principal, aparece apenas em um momento do livro. $E$, mesmo assim, como uma referência indireta, ao discutir a doutrina oficial da RDA acerca da interpretação do nazismo. 
Duas indagações me parecem, ainda, dignas de destaque. Em que medida o regime nazista contou com a aprovação do povo alemão? Em que medida constituiu um fenômeno singular, produto de uma história e de uma conjuntura específicas? Seleciono estas duas questões porque elas se prestaram e ainda se prestam a uma longa controvérsia, com repercussões no terreno político.

No que diz respeito à primeira, Elias não fica encerrado no dilema responsabilidade coletiva ou absolvição do povo alemão, optando por uma análise mais ampla. Não nega que muitos alemães recusaram o nazismo e, esquecendo os militantes de esquerda liqüidados em grande número nos campos de concentração, lembra o fracassado atentado contra a vida de Hitler, praticado por oficiais de alta patente, nos últimos anos da guerra.

Porém, a ênfase não é colocada na resistência e sim na aceitação ou no entusiasmo pelo nacional-social ismo, ponto de vista coerente com toda a sua análise. No fundo, diz Elias, nenhuma oposição ou revolta era possível, tanto pela coação estatal quanto porque a consciência, o autocontrole da grande massa permaneceu, em grande medida, dependente do Estado, quaisquer que fossem seus representantes. As técnicas intensivas de educação e de propaganda, postas em prática pelos nazistas no sentido de garantir a lealdade absoluta da população, serviram apenas para reforçar as características de uma estrutura de personalidade que criou nos indivíduos uma disposição a se submeter lealmente às exigências do chefe do Estado, cuja imagem foi internalizada pelo povo como parte de sua consciência.

A análise, concentrada na psicologia coletiva, é oscilante. O texto acima referido implica uma identificação não conflituosa entre o povo alemão e Hitler, considerando-se o habitus forjado ao longo da história alemã e a personalidade deste, cujas necessidades emocionais correspondiam às de seus seguidores. Entretanto, ao mesmo tempo, Elias faz referência à identificação com o opressor, a despeito de todo o ódio e dúvidas que muitos alemães podem ter sentido no fundo de seus corações.

A questão da singularidade do nazismo, simplificadamente, pode ser encarada através de duas interpretações opostas. De uma lado, a que considera o nazismo um regime específico, nascido de uma conjunção de fatores estruturais e conjunturais não reprodutíveis, distinguindo-se inclusive do fascismo. De outro, aquela que, a partir principalmente da análise do Holocausto, relativiza a chamada peculiaridade dos alemães, considerando o nacional-socialismo uma forma da barbárie gerada pela "modernidade" 2 . 
Em algumas passagens, Elias aproxima-se da última linha interpretativa, ainda que não se identifique com ela. Ao se referir às explicações que consideram o nazismo um câncer extirpável no corpo das sociedades civilizadas, diz que elas trazem conforto mas não explicam grande coisa. M uitos eventos recentes sugerem que o nacional-socialismo revelou, de uma forma particularmente execrável, condições comuns às sociedades contemporâneas.

Porém, a discussão me parece deslocada. Se os exemplos da atualidade demonstram a extensão do genocídio, em uma escala inimaginável nos primeiros anos posteriores à Segunda Guerra M undial, a questão da especificidade do nazismo não se reduz a essa constatação, mas às suas características peculiares que não se limitam ao Holocausto, por mais dramático que este tenha sido.

Por último, caberia pensar sobre as possibilidades de reemergência do nazismo na Alemanha, não apenas como um fenômeno marginal. Elias não lida diretamente com a questão, mas afirma que, no plano político, a interiorização de um regime parlamentar multipartidário, por parte do povo alemão, é tarefa para alguns séculos, pois um regime dessa natureza, baseado na mediação e no compromisso, choca-se com os valores autoritários e guerreiros, cristalizados ao longo da história da Alemanha.

Em um registro otimista, poderíamos nos perguntar se a Segunda Guerra Mundial e os acontecimentos posteriores não abriram caminho para uma inflexão de habitus da população alemã. Duas guerras com desfechos catastróficos para a Alemanha e as lições aprendidas pelos países democráticos em sua atitude para com os vencidos, tão diversas em 1918 e em 1945, não teriam, ao menos, contribuído significativamente para livrar os alemães de uma síndrome histórica?

Recebido em 11 de setembro de 1997

Reapresentado em 4 de janeiro de 1998

Aprovado em 29 de janeiro de 1998

Boris Fausto é historiador e professor aposentado do Departamento de Ciência Política da USP. Editor da História Geral da Civilização Brasileira (Período Republicano) e autor, entre outros trabalhos, de Crime e Quotidiano. A Criminalidade em São Paulo (1880-1924) (1984) e História do Brasil (1994). E-mail: bfausto@netserv.com.br 


\section{Notas}

1 Isto não quer dizer que as explicações microconjunturais tenham desaparecido de cena. Para um exemplo recente, ver Turner J r. (1997).

2 Este último argumento é central para os historiadores que tentaram relativizar o genocídio nazista, gerando a "querela dos historiadores", aberta por Habermas, em 1986, com sua crítica ao "revisionismo conservador". Dentre os autores criticados, destaca-se, por seu prestígio, Ernst $\mathrm{N}$ olte. Nolte argumenta que, embora o genocídio tenha sido incontestável e deplorável, estaria inscrito em uma série de eventos comparáveis, característicos do século XX. M ais ainda, ele não teria ocorrido, se não fosse o genocídio cometido pelos bolcheviques russos, por razões de classe (ver Nolte 1988).

\section{Referências bibliográficas}

ADORNO, T. W. et alii. 1950. The Authoritarian Personality. New York: Harper \& Row.

ELIAS, N orbert. 1993. O Processo Civilizador. Rio de J aneiro: J orge Zahar Ed.

FURET, François. 1995. O Passado de uma Ilusão. Ensaios sobre a Idéia Comunista no Século XX. São Paulo: Ed. Siciliano.
NOLTE, Ernst. 1988. “Un Passé qui ne Veut pas Passer". In: B. Vergne-Cain (org.), Devant l'H istoire. Documents de la Controverse sur la Singularité de l'Extermination des J uifs. Paris: Cerf.

TURNER J R., Henry A. 1997. Hitler's Thirty Days to Power: J anuary 1933. Cambridge: Addison Wesley. 
Resumo

Este trabalho analisa um dos temas centrais do último livro de Norbert Elias: a significação do nazismo. Refere-se às razões da perplexidade das correntes liberal e marxista para dar conta do fenômeno, pelo menos em um primeiro momento. A partir dessa constatação, expõe o ponto de vista de Elias, que se aparta de uma história-progresso, no rumo de um processo civilizatório cada vez mais aperfeiçoado. Procura-se demonstrar como a interpretação de Elias está fundada na análise de longa duração da história alemã, dando relevância à constituição do habitus como um conceito explicativo original que não se confunde com o de caráter nacional. O ensaio discute também o peso secundário, embora não irrelevante, que Elias atribui à conjuntura dos anos 20 e princípios dos anos 30 na implantação do nazismo. Indaga-se, por último, se, na opinião de Elias, o nazismo foi um fenômeno datado e específico e, em função da resposta, quais as possibilidades de sua reemergência no quadro atual.

\section{Abstract}

This paper analyzes the significance of $\mathrm{N}$ azism, one of the central themes in the latest book by Norbert Elias. It refers to the reasons behind the perplexity of the liberal and Marxist currents in dealing with the phenomenon, at least initially. Beginning with this observation, the author presents Elias' point of view, which strays from a kind of progress-history towards an increasingly perfected civilizatory process. It seeks to demonstrate how Elias' interpretation is founded on a long-range analysis of German history, highlighting the constitution of habitus as an original explicatory concept, not to be confused with that of national character. The essay also discusses the secondary (albeit relevant) weight Elias ascribes to the context of the 1920s and early 1930s in implanting $\mathrm{N}$ azism. Finally, the author asks whether in Elias' view Nazism was a dated, specific phenomenon and - depending on the answer - what the possibilities might be for its reemergence in the current context. 